Jackendoff $\mathrm{R}$ (1997). The architecture of the language faculty. Cambridge, MA: MIT Press.

Jackendoff R (2002). Foundations of language: brain, meaning, grammar, evolution. Oxford: Oxford University Press.

Jun J S (2003). 'Syntactic and semantic bases of case assignment: a study of verbal nouns, light verbs, and dative.' Ph.D. diss., Brandeis University.

Katz J J (1980). 'Chomsky on meaning.' Language 56(1), $1-41$.

Katz J J \& Fodor J A (1963). 'The structure of a semantic theory.' Language 39(2), 170-210.

Labov W (1973). 'The boundaries of words and their meanings.' In Bailey C -J N \& Shuy R W (eds.) New ways of analyzing variation in English, vol. 1. Washington, DC: Georgetown University Press.

Levin B (1993). English verb classes and alternations. Chicago: University of Chicago Press.

Marr D (1982). Vision. San Francisco: W. H. Freeman.
Piñango M M, Zurif E \& Jackendoff R (1999). 'Real-time processing implications of aspectual coercion at the syntax-semantics interface.' Journal of Psycholinguistic Research 28(4), 395-414.

Pustejovsky J (1995). The generative lexicon. Cambridge, MA: MIT Press.

Swinney D (1979). 'Lexical access during sentence comprehension: (re)consideration of context effects.' Journal of Verbal Learning and Verbal Behavior 18, 645-659.

Wertheimer M (1912). 'Experimentelle Studien über das Sehen von Bewegung.' Zeitschrift für Psychologie 61, 161-265.

Zurif E \& Blumstein S (1978). 'Language and the brain.' In Halle M, Bresnan J \& Miller G A (eds.) Linguistic theory and psychological reality. Cambridge, MA: MIT Press. 229-245.

Zurif E, Caramazza A \& Myerson R (1972). 'Grammatical judgments of agrammatic aphasics.' Neuropsychologia 10, 405-417.

\section{Lexical Conditions}

P A M Seuren, Max Planck Institute for

Psycholinguistics, Nijmegen, The Netherlands

(c) 2006 Elsevier Ltd. All rights reserved.

In many schools of linguistics it is assumed that each sentence $S$ in a natural language has a so-called semantic analysis (SA), a syntactic structure representing $S$ in such a way that the meaning of $S$ can be read off its SA in a regular way. The SA of a sentence $S$ is distinct from its surface structure (SS), which corresponds directly with the way $S$ is to be pronounced. Each language has a set of rules, its grammar G, defining the relationship between the SAs and the SSs of its sentences. The SA of a sentence $S$ is often also called its logical form, because the SA exhibits not only the predicate-argument structure of $S$ and its embedded clauses if $S$ has any, but also the logically correct position of tense, quantifiers, negation, modalities, and other possible operators besides all the meaningful lexical items of the corresponding SS. SAs are thus analytical as regards their structure, not as regards their lexical items. The lexical items of SSs are in place in SAs: in principle, SAs provide an analysis that goes as far as the lexical items and stops there. SAs do not specify lexical meanings.

Lexical meanings are normally specified in dictionaries, but dictionaries do so from an SS point of view. However, linguistic theories assuming an SA-level of representation for sentences require that lexical meanings be specified at SA-level. The difference is that, at SA-level, lexical items are allowed to occur only in predicate positions. A surface sentence like (1a) is represented at SA-level as (1b), written as the linear formula (1c) and read intuitively as (1d):

(1a) The farmer was not working on the land.

(1b)

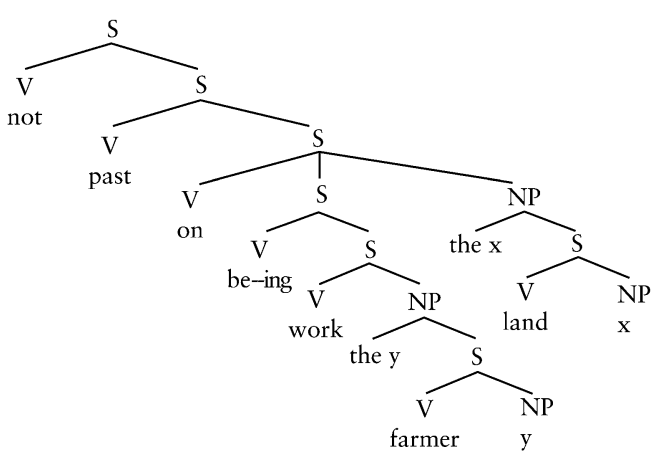

(1c) S[V[not] S[V[past] S[V[on] S[V[be] S[V[work] $\mathrm{NP}[$ the y S[V[farmer] NP[y]]]]] $\mathrm{NP}[$ the $\mathrm{x}$ S[V[land] $\mathrm{NP}[\mathrm{x}]]]]]]$

(1d) It is not so that in the past on the land the farmer was working.

The items not, past, on, be-ing, work, farmer, and land are all labeled ' $\mathrm{V}$ ', which makes them predicates in (1b). In (1a), however, farmer is a noun, the past tense is incorporated into the finite verb form was, not is usually considered an adverb, working is a present participle in the paradigm of the verb work, on is a preposition, and land is again a noun. 
Because predicates express properties, the question is what property the predicates at issue assign to what kind of objects. Not assigns the property of being false to the proposition in its scope. (Finnish and cognate languages use verbs for the negation: 'John nots working' for 'John does not work.') Past places its proposition in a given past time. On says that the farmer's being at work is on the land. (Some American Indian languages say 'the farmer's working on-s the land,' with on as a verb.) Be-ing stretches the farmer's working out over a period of time. Farmer and land assign the property of being a farmer, or land, to the values of their variables. Thus, despite differences in surface categories, all lexical words can be regarded as predicates at SA level.

Analyzing all lexical meanings as predicate meanings has the advantage of a uniform format of lexical specification for all lexical items. The format is that of a definition of satisfaction conditions or lexical conditions. The lexical conditions of an $n$-ary predicate $\mathrm{P}^{\mathrm{n}}$ define the property assigned by $\mathrm{P}^{\mathrm{n}}$. They are the conditions that must be fulfilled by any object (or $n$ - tuple of objects) $o$ for $o$ to deserve $\mathrm{P}^{\mathrm{n}}$, in the sense that when $\mathrm{P}^{\mathrm{n}}$ is applied to $o$, a true proposition results. Thus, for example, the conditions that determine whether a sentence like This animal is a dog is true are the lexical conditions associated with the predicate $d o g$, applied to whatever object is referred to by the definite term this animal. Only if that object fulfills the conditions that are necessary for doghood is the sentence true. Generally, the extension $\left[\left[\mathrm{P}^{\mathrm{n}}\right]\right]$ of the predicate $\mathrm{P}^{\mathrm{n}}$ is the set of $n$ - tuples of world objects $o$ that fulfill the conditions set for $\mathrm{P}^{\mathrm{n}}$. Or:

(1) $\left[\left[\mathrm{P}^{\mathrm{n}}\right]\right]=\left\{<\mathrm{o}_{1}, \ldots, \mathrm{o}_{\mathrm{n}}>\mid \ldots\right.$ (lexical conditions) $\left.\ldots\right\}$

It is important to note that the lexical conditions thus specified do not, generally, exhaust the meaning of a predicate, even though lexical conditions can be formulated with great subtlety. Meanings often have vague boundaries, which makes the formulation of lexical conditions difficult. Words are often polysemous in that they have different but related meanings, such as the word chest, which applies either to a box meant for storage or to the part of a human body that is enclosed by the ribs. Polysemy often leads to homonymy or near homonymy (again with vague boundaries), as in the case of table (piece of furniture, slab of stone with symbols on it, or well-ordered list of data) or leaf (of a tree or of a book). Moreover, there is often dynamic filtering in word meanings, as in The office is on fire versus The office has a day off. In the former, the term the office denotes a building, in the latter a group of employees. The difference is caused by the nature of the predicate: be on fire requires a combustible object, whereas have a day off requires humans under a statute imposing duties, but how to integrate such possible referential differences into the format shown in (1) is unknown (and largely undiscussed in the literature). Then there is object dependency, as with verbs of cutting: one cuts the grass, one's hair or nails, one's finger, and the meat (though cutting one's finger is very different from cutting the meat); one trims the hedge and the dog, and sometimes one's hair also; one tailors a suit (German: schneiden); one gelds a horse (French: couper), etc. It is such phenomena that make it hard to use the format shown in (1) for the practical purposes of dictionaries.

In one respect, the format of (1) can be refined. Presuppositions are naturally accounted for by making a distinction between two kinds of lexical conditions, preconditions and update conditions (see Presupposition). Presuppositions are derivable from the preconditions of SA-predicates (see Fillmore, 1971; Seuren, 1985: 266-313). Consider the predicate be divorced. For someone to be divorced, they must have been married first. Or the predicate be back: for someone to be back, they must have been away first. The conditions of having been married first or having been away first are the preconditions of these predicates. The condition that the marriage has been dissolved, or that the person in question is no longer away, is the update condition.

When a precondition is not fulfilled, the sentence suffers from presupposition failure, a condition that, according to some (in particular Strawson, 1950), leads to a lack of truth value and according to others (Blau, 1978; Seuren, 1985), to a third truth value, strong or 'radical' falsity. If an update condition is not fulfilled, the sentence is simply, or minimally, false. In presupposition theory, the lexical conditions of a predicate $\mathrm{P}^{\mathrm{n}}$ can thus be presented in the following general format:

$$
\begin{aligned}
& \text { (2) }\left[\left[\mathrm{P}^{\mathrm{n}}\right]\right]=\{<\mathrm{o} 1, \ldots \text {, on }>: \ldots \text { (preconditions) } \ldots \text {. I } \\
& \text {... (update conditions)...\} }
\end{aligned}
$$

This format is exemplified in, for example, the following specification for be divorced:

(3) $\left[\left[\right.\right.$ be divorced $\left.\left.^{1}\right]\right]=\{$ o : o was married lo's marriage has been legally dissolved $\}$

Or: 'the extension of the predicate be divorced is the set of entities $o$ such that $o$ (precondition) was married, and (update condition) o's marriage has been legally dissolved'.

See also: Discourse Domain; Discourse Semantics; Multivalued Logics; Presupposition. 


\section{Bibliography}

Blau U (1978). Die dreiwenige logik der sprache. Ihre syntax, semantik und anwendung in der sprachanalyse. Berlin: De Gruyter.

Fillmore C J (1971). 'Types of lexical information.' In Steinberg D \& Jakobovits L (eds.) Semantics. An interdisciplinary reader in philosophy linguistics and psychology. Cambridge: Cambridge University Press. 370-392.

Seuren P A M (1985). Discourse semantics. Oxford: Blackwell.

Strawson P F (1950). 'On referring.' Mind 59, 320-344.

\section{Lexical Fields}

P Lutzeier, University of Surrey, Surrey, UK

(C) 2006 Elsevier Ltd. All rights reserved.

\section{Introduction}

Lexical fields have an immediate intuitive appeal. The reference to one or two examples like the field of verbs of motion walk, run, skip, ... or the field of adjectives of emotion happy, angry, disappointed,... normally is enough to give the feeling that one knows what we are talking about. A widespread curiosity about words also helps, not the least in the context of being a parent and trying to collect the child's first words. At the same time, one cannot help noticing that textbooks very rarely go beyond the mere mentioning of lexical fields in form of a few examples, plus perhaps some critical remarks about the apparent lack of rigor around the concept. In other words, the intuitive strength of the concept may go together with some theoretical vagueness. Nonetheless, what remains at this stage is the widespread appeal of the concept and undoubtedly successful application of the concept in several disciplines:

- Lexicology, Semantics and Cognitive Linguistics. Lexical fields are a useful tool for holistic approaches about lexical meaning, structures of the vocabulary and mental lexicon as well as issues around categorization.

- Lexicography. The codification of the vocabulary of a language can be done in several different formats, and the organization of entries around lexical fields is one of them and leads to specialized dictionaries.

- Psycholinguistics. Lexical fields are employed in connection with word memory tests, explorations on language acquisition and language loss.

- Anthropology. Lexical fields are a useful tool in fieldwork on the language and culture of societies. This remains a major area in the context of globalization and 'Global' English, and the concern about endangered languages.
- Medical Neuroscience and Clinical Linguistics. Lexical fields are used for the investigation of different forms of aphasia.

In addition to the term 'lexical field,' there are other terms in use, such as 'word field' and 'semantic field'; but we shall confine ourselves to lexical field, which provides greater flexibility, because, in contrast to word field, it implies that the relevant groupings involve lexical elements and these are not necessarily confined to words. At least in theory idioms can be contemplated as possible members of such groupings. We also prefer lexical to semantic because the relevant groupings are parts of the lexicon, and its elements will consist of a form level as well as of a content level.

\section{Background}

Lexical fields contribute to structuring the lexicon and to exploration of lexical meaning. Although the lexical meaning of any member of the lexicon must be seen as a holistic entity, this does not preclude its conception as something internally structured. This structure must make provision for phenomena such as monosemy and polysemy; and, for each individual sense, phenomena such as prototypicality, stereotypes, and family resemblances need to be incorporated. In addition, the outer boundaries of the lexical meaning/senses of any member of the lexicon will be established by finding its unique position in the content plane of the lexicon. This happens in contradistinction to other similar lexical meanings along the paradigmatic dimension and in connection with other different, but compatible lexical meanings along the syntagmatic dimension. The paradigmatic dimension is mainly captured by membership in the same lexical fields and by means of sense relations, but also partly by associations. The syntagmatic dimension is mainly captured by collocations, but also partly by associations.

Whichever structure one adopts for the lexical meaning, it cannot be a static one. One has to take 